\title{
Inhomogeneity of Microstructure of Aluminum Alloy Welded Joint
}

\author{
Xian-Min TANG ${ }^{a}$, Hai-Gen JIAN ${ }^{b, ~}{ }^{,}$, Jing-Fang WU ${ }^{c}$, Ling OU ${ }^{d}$ \\ School of Metallurgical Engineering, Hunan University of Technology, Zhuzhou, 412007, China \\ a1109754661@qq.con, b, jianhaigen2001@163.com, '872181355@qq.com, d23743343@qq.com \\ ${ }^{*}$ Corresponding author
}

Keywords: MIG Welding, Inhomogeneity of Microstructure, Welding Seam, Coarse Grain Zone.

\begin{abstract}
Al-Mg-Mn alloy hot-rolled plates with $10 \mathrm{~mm}$ thick were welded by multipass MIG welding with the Al-Mg wire, and inhomogeneity of microstructure of the welded joint were examined by the methods of metallograph, scanning electron microscope (SEM) and energy spectrum. The results show that the inhomogeneity of microstructure is very obvious in different regions of welded joint. The weld zone is typical cast microstructure, heat affected zone (HAZ) retains the basic characteristics of hot-rolled and partial recrystallization occurs. Because of the grain refining effect of $\mathrm{Al}_{3} \mathrm{Zr}$ particle, a layer of fine grain structure, in which the grains are remarkably fine, is formed on the weld pool boundary. In two cladding welding interface, because of the similarity of microstructure of both sides, weld grains grow epitaxially along the heat dissipation direction and grain growth is more apparent.
\end{abstract}

\section{Introduction}

$\mathrm{Al}-\mathrm{Mg}$ alloy is a typical non-heat-treatment-strengthening alloy with medium strength, weldability, corrosion resistance and other characteristics, widely used in upper structure and outfitting of large vessels [1-2]. Considering load and corrosive environment the hull structure suffered, Al-Mg-Mn alloy used in the research is the basic marine structure welding materials. The role of the ship welding technology plays in improving shipbuilding productivity and reducing costs and weight cannot be discounted [3-4]. There are a lot of welding methods such as gas metal arc welding, tungsten inert gas arc welding (TIG), and friction stir welding (FSW). After decades of development, the welding equipment, materials and process of MIG welding become mature. Currently, MIG welding is not only the most used welding method, but also the preferred method in automatic line and welding robot. More than 90\% aluminum alloy welding adopts MIG method at home and abroad [5-8].

Currently, there are already many researches on Al-Mg alloys welding and its welded joints, but study on inhomogeneity of microstructure of multipass welding welded joints is rarely reported [9-11]. In this paper, $\mathrm{Al}-\mathrm{Mg}$ wire is chosen to weld Al-Mg-Mn alloy hot-rolled plates with $10 \mathrm{~mm}$ thick by multipass MIG welding, and inhomogeneity of microstructure were carefully examined by metallographic, scanning electron microscope (SEM) and energy spectrum analysis. Furthermore, formation and growth mechanisms of coarse grain on fine grain layer of weld pool boundary and bead interface regions.

\section{Experiment}

Using 10mm thick Al-Mg-Mn alloy hot-rolled plates as welding substrate, of which the main chemical composition (wt \%) is: $\mathrm{Mg} 6.58, \mathrm{Mn0.55}, \mathrm{Cr} 0.2, \mathrm{Zr0} .15, \mathrm{Al}$ margin. Al-Mg alloy wire is selected as the filler metal, of which the main chemical composition is similar to substrate [12]: Mg5.73, Mn0.49, Cr0.15, Zr0.15, Al margin.

Cleaning weldment before welding: wiping surface with acetone or alcohol, then polishing weld area with brush. A V-shaped groove was made, Panasonic YD-400GE welder was selected in the experiment, and MIG manual welding was performed under the protection of single $99.99 \%$ inert Ar gas. 3 layer \& 4-pass welding method was adopted: the first layer was backing weld; the second layer 
was filling weld; the third layer was two-pass cladding weld. The structure of welded joints is showed in Figure 1.

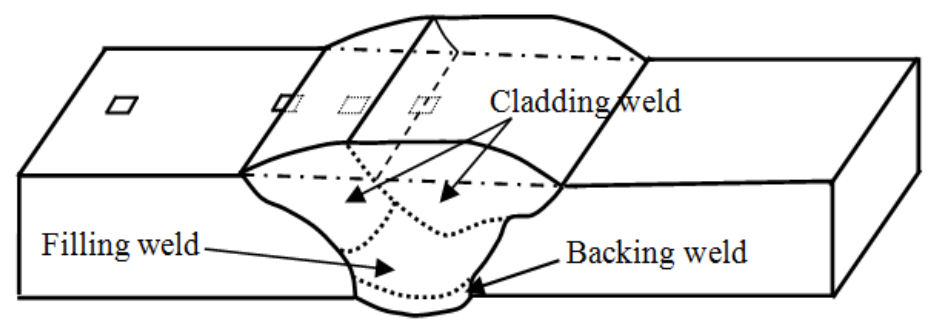

Fig.1 Structure of welded joint

Before the test, the weld reinforcement was removed. Key experimental points, such as heat affected zone, molten pool boundary, weld zone and bead interface, were examined by metallographic and scanning electron microscope (SEM). The sampling regions are showed in Figure 1. Anodic coating had to be done before the metallographic observation of microstructure, with the solution ratio of $1000 \mathrm{mlH}_{2} \mathrm{O}+30 \mathrm{mlHF}+11 \mathrm{gH}_{3} \mathrm{BO}_{3}$, the $0.1 \sim 0.2 \mathrm{~mA}$ current and 90 s coating time. Scanning morphology observation and energy spectrum analysis of welded joint were performed on HITACHI S-3400 scanning electron microscope.

\section{Results and Discussion}

Microstructure of welded joints observed in the metallographic microscope are showed in Figure 2, substrate, heat affected zone, fusion zone, weld zone and coarse grain zone are showed in a) to d) respectively.
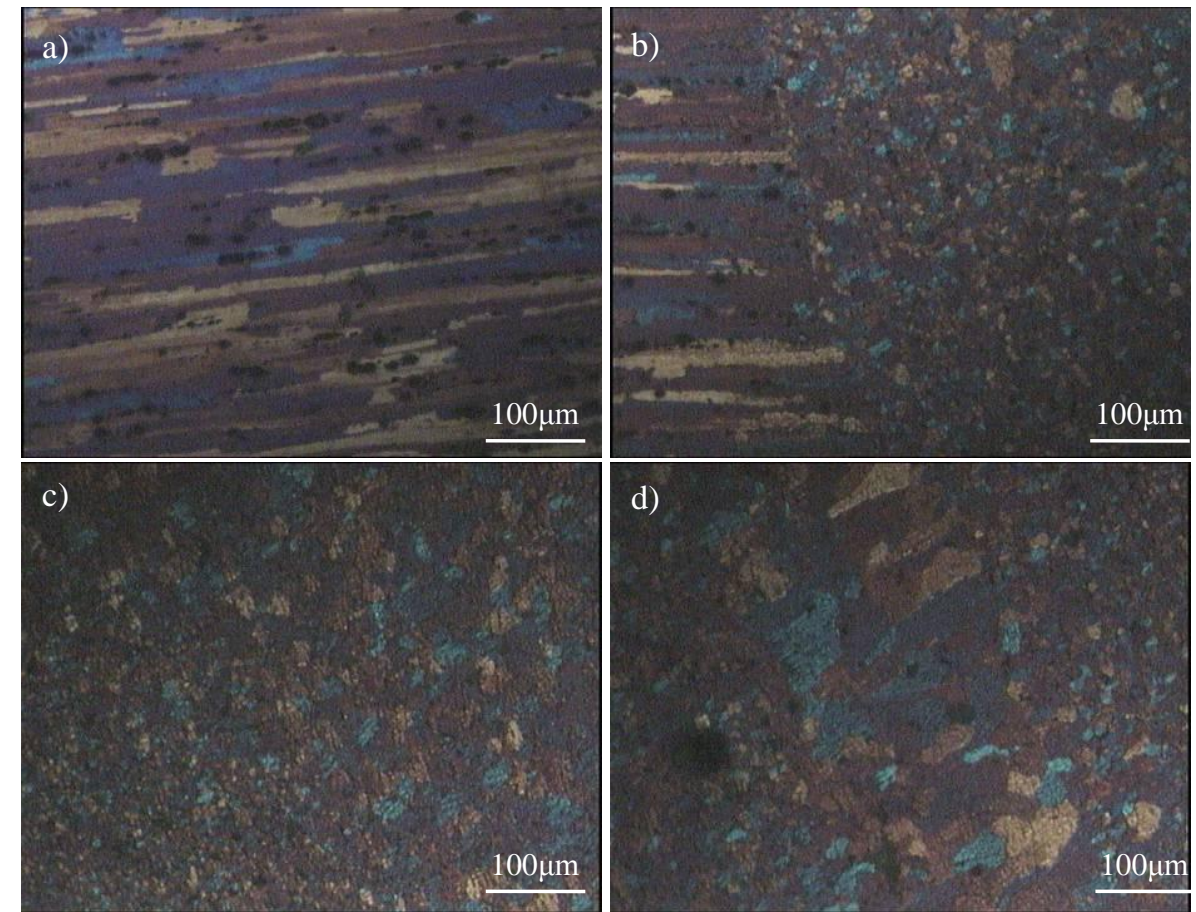

a) substrate; b) HAZ and fusion zone; c) weld zone; d) coarse grain zone

Fig.2 Microstructure of different regions of welded joint

Welding substrate are typical rolling strips, in which coarse grains with various sizes that has not re-dissoluted in the rolling process are observed, and distribute along the extrusion direction. Recrystallization occurs to certain degree in the heat affected zone, mainly manifesting as the grain size coarsening. The weld zone is typically cast microstructure, and grains are relatively coarse (about $20 \mu \mathrm{m})$. There is a layer of fine grains, of which grains are very small (about a few microns), on the interface of substrate and weld zone. While a coarse grain zone, of which grains are coarse and 
growing along heat dissipation direction, the largest grain is more than $100 \mu \mathrm{m}$, exists between the two beads. This reason is that, in a multi-pass welding process, the weld area of former bead becomes the heat-affected zone and pool boundary of the later bead. Both sides of the bead border are the same cast organization, having the same crystal structure. Structural similarity reduces the grain misorientation, and is very conducive to the grain epitaxial growth. In the process of consolidation and growth, grains show certain directionality along the heat dissipation path.

Each zone of welded joints is observed by SEM, and the results are shown in Figure 3. Seen from the results, boundary between weld zone and HAZ is obvious. Coarse grains can be seen in the HAZ which are similar to those in substrate. There is precipitation both within the grain and on the grain boundary, while the latter is dominant. The reason is that, in the weld cooling process, grains grow and contact each other, materials of low melting point is prone to forming segregation on the grain boundary. Meanwhile, larger weld porosities can also be seen in the coarse grain zone.
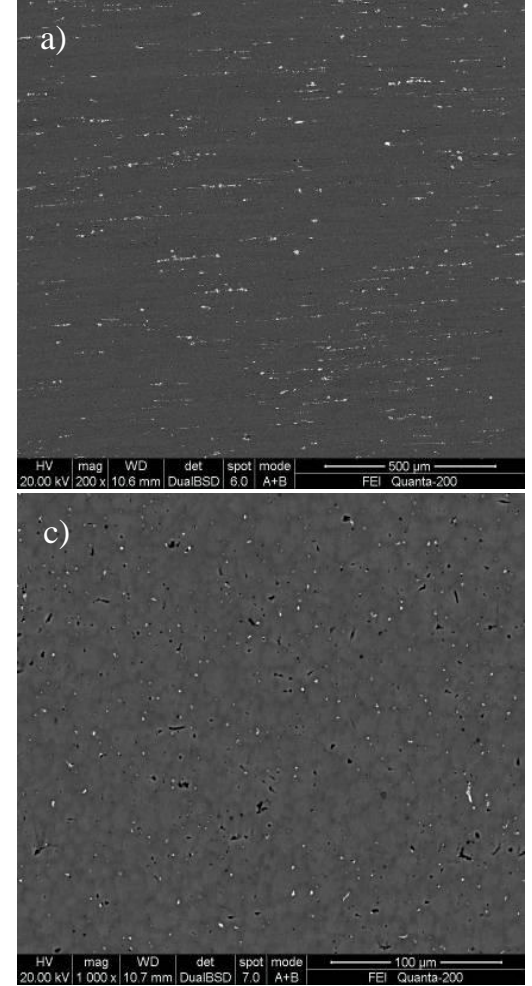

a) substrate; b) HAZ and fusion zone; c) weld zone; d) coarse grain zone
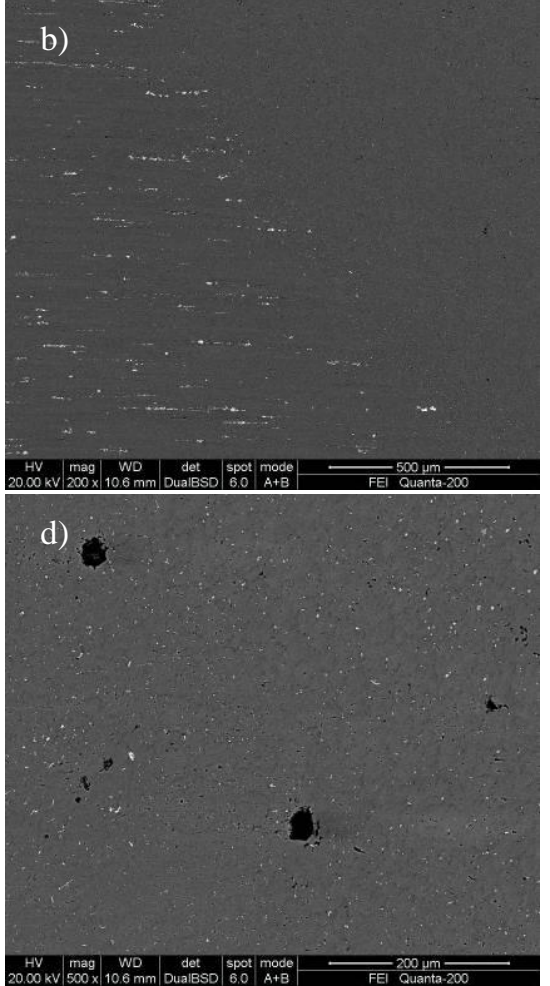

Fig. 3 SEM micrograph of the regions of welded joints

In terms of overall morphology, distribution of the second phase, and the size of the grain, the differences between different zones of welded joints shows great inhomogeneity. To further investigate causes of regional inhomogeneity of microstructure of welded joint, energy spectrum analysis is applied to fine grain layer, weld zone and coarse grain zone respectively. Results are shown Table 1.

On the basis of the analysis results, apart from burning loss and volatilization, there are no much difference of elemental composition between coarse grain zones and weld zone. A certain amount of $\mathrm{Zr}$ and $\mathrm{Cr}$ are found in fine grain layer, which is the main reason for the existence of the fine grain layer on the molten pool boundary. After homogenization and subsequent hot rolling process, a large number of $\mathrm{Al}_{3} \mathrm{Zr}$ particles exist in substrate. These $\mathrm{Al}_{3} \mathrm{Zr}$ particles are very similar to $\alpha(\mathrm{Al})$ substrate in lattice type ( $\mathrm{LI}_{2}$ type) and lattice size, and the misfit ratio is very small. In the welding condensing process, these particles as favorable heterogeneous nucleus primarily precipitate in the molten pool wall, thereby forming a layer of fine grain structure in the pool interface. In the weld zone, only a small amount of primary $\mathrm{Al}_{3} \mathrm{Zr}$ particles formed, which plays a role in weld grain refinement, and grain size of the weld zone is about $20 \mu \mathrm{m}$. 
Tab.1 Energy spectrum analysis results of different regions of welded joints

\begin{tabular}{ccccc}
\hline Detection area & Element & Series unn. [wt.\%] & C norm. [wt.\%] & C Atom. [at.\%] \\
\hline \multirow{5}{*}{ Weld zone } & Oxygen & 0.45 & 0.36 & 0.94 \\
& Magnesium & 4.81 & 5.98 & 6.6 \\
& Aluminium & 74.41 & 92.4 & 91.94 \\
& Manganese & 0.86 & 1.27 & 0.52 \\
& Oxygen & 0.16 & 0.24 & 0.26 \\
Coarse grain zone & Magnesium & 4.91 & 5.95 & 6.51 \\
& Aluminium & 77.48 & 92.59 & 92.56 \\
& Manganese & 1.15 & 1.22 & 0.67 \\
& Magnesium & 5.18 & 5.85 & 6.48 \\
& Aluminium & 81.75 & 92.32 & 92.12 \\
& Manganese & 0.91 & 1.03 & 0.5 \\
& Oxygen & 0.39 & 0.44 & 0.73 \\
& Zirconium & 0.09 & 0.1 & 0.03 \\
& Chromium & 0.24 & 0.27 & 0.14 \\
\hline
\end{tabular}

\section{Conclusions}

Aluminum alloy welded joint by multipass MIG welding consists of heat affected zone, fine grain layer, weld zone and coarse grain zone, and the inhomogeneity of microstructure is obvious. Because of the grain refinement effect of Al3Zr particle, grains in weld zone are refined to about $20 \mu \mathrm{m}$, forming a layer of fine grain in the molten pool boundary. In the two-pass cladding weld interface, due to the similarity of both sides of the interface structure, grains consolidate and growth following epitaxial growth mechanism in the welding condensing process, showing a clear directionality.

\section{Acknowledgements}

This work was financially supported by the National Science Foundation of China (51301065), and Natural Science Foundation of Hunan Province (14JJ7067).

\section{References}

[1] S. J. Chen, Y. Xia, Y. Yu: Rare Metal Mat. Eng. Vol. 41(2012), p. 352.

[2] B. H. Luo, Y. M. Shan, Z. H. Bo: J. Cent. South Univ. Vol. 38(2007), p. 802.

[3] A. H. Clausen, T. Borvik, O. S. Hopperstad: Mater. Sci. Eng. A Vol. 364(2004), p. 260.

[4] W. Y. Zhang: Light Metals Vol. 4(2010), p. 53.

[5] Z. H. Yang, X. C. Sun: Aluminium Fabrication Vol. 153(2003), p. 19.

[6] G. H. Luan: Electric Welding Machine Vol. s1(2004), p. 98.

[7] J. H. Xie, H. Chen, J. J. Zhao: Electric Welding Machine Vol. 41(2001), p. 81.

[8] J. Zhao, F. Jiang, H. G. Jian: Mater. Des. Vol. 31(2001), p. 306.

[9] S. L. Li, Q. L. Pan, X. M. Chen: Ordnance Mater. Sci. Eng. Vol. 26(2003), p. 11.

[10] Y. H. Xie, S. J. Yang, S. L. Dai: J. Aeronaut. Mater. Vol. 22(2002), p. 56.

[11]F. Jiang, Z. M. Yin, B. Y. Huang: J Rare Earths. Vol. 22(2004), p. 600.

[12] H. G. Jian, X. E. Xie, B. Shan: J. Hunan Univ. Tech. Vol. 27(2013), p. 81. 